\title{
Histopathological changes in the internal organs of female striped gourami (Trichogaster fasciata) exposed to sub-lethal concentrations of salt water
}

\author{
WATINI REZA, MD. TAREQUL ISLAM, MD. HELAL UDDIN, \\ KIZAR AHMED SUMON AND HARUNUR RASHID* \\ Department of Fisheries Management, Bangladesh Agricultural University \\ Mymensingh 2202, Bangladesh \\ *Email: rashid@bau.edu.bd
}

\begin{abstract}
The present study was conducted to evaluate the effects of climate induced salinity on histoarchitecture of liver, kidney and ovary tissue of female striped gourami (Trichogaster fasciata) exposed to three sub-lethal concentrations (3, 6 and $9 \mathrm{ppt})$ of crude salt along with a control group (0 ppt) for a period of 30 days. The 96-h LC50 value of crude salt for striped gourami was previously estimated as $11.107 \mathrm{ppt}$. To conduct the experiment 12 plastic tanks each having 70L water holding capacity were used for the four treatments with three replications for each. Water exchange was done on every 10th day and crude salt was used to maintain desired salinity. Several histopathological changes were observed in fish liver, kidney and ovary exposed to different concentrations of salinity. Increasing necrosis, hemorrhage, hepatic rupture, melano-macrophage cells, degenerated cell and vacuums in the liver tissue were found in salt water treated groups. Similarly, a number of changes such as, vacuole, cellular degeneration, hemorrhage, disintegrated glomeruli, destructed renal tubule and extensive vacuolein were observed in the kidney tissue of salt water treated groups. Degenerated oocyte, inter-follicular space, disrupted oocytes, etc. were observed in ovary with increasing concentration of salinity and time of exposures. Physiological and metabolic dysfunctions might have happened to female stripped gourami due to changes in vital internal organs like liver, kidney and ovary. Therefore, the present research further suggested that climate induced salinity intrusion is capable of stressing freshwater fishes resulting in deformities of liver, kidney and ovary.

Keywords: Salinity, Histopathology, Striped gourami, Ovary
\end{abstract}

\section{Introduction}

Climate change is now a burning question all over the world. Effects of climate change include increase in ocean temperature, changes in $\mathrm{pH}$ and precipitation, corresponding upstream river discharge and rising sea level and recognized as a critical environmental problem of the 21st century (Bhuiyan and Dutta 2012). Coastal zones are considered as most productive ecosystems but vulnerable to climate change effects. Sea level rise may affect freshwater quality by increasing the salinity of coastal rivers and bays due to salt water intrusion (Zhang et al. 2011). Several environmental factors, such as light, temperature, $\mathrm{pH}$ and salinity primarily control the growth of fish (Overton et al. 2008). Salinity is a crucial environmental factor affecting physiological performances in freshwater organisms and represents one of the main natural sources of stress shaping the biodiversity.

Freshwater fish species exposed to salt waters for a significant period of time results in modification or inactivation of organism's internal organs especially kidney, liver, gill morphology, integument, spleen, hematological parameters and behavior such as surface 
HISTOPATHOLOGICAL CHANGES IN STRIPED GOURAMI EXPOSED TO SALT WATER

movement, erratic movement, change in swimming rate, opercula movement and may also affect on survival (Amin et al. 2016). Due to high metabolic activities liver, kidney, ovary and gill are some of the internal organs in fish where environmental contaminants exert their effects (Oruce and Usta 2007). In teleosts, kidney is one of the first organs to be affected by contaminants in the water (Hadi and Alwan 2012). It is an important function to maintain the actual level of salinity to ensure a high growth rate and lower energetic cost of osmoregulation (Jahan et al. 2019). Renal lesions are considered as good environmental indicators since fish kidney is the recipient of larger proportion of post-branchial blood (Ortiz et al. 2003). In fish, as in higher vertebrates, important physio-biochemical functions like water balance, electrolyte balance and maintenance of stable internal environment, are all performed by kidney (Cengiz et al. 2006). Due to salinity the kidney suffers from hydropic degeneration, edema and necrosis which lead them to death (Jashim 2013). Fish liver is considered as a major portion of storage, biotransformation and excretion of natural and chemical pollutants (Velmurugan et al. 2007). Liver cell degeneration hampers the physiological function such as hematological parameters, restlessness, hormonal imbalance and degeneration of ovary cell that cause decreased hemoglobin, reduced productive performance and low survival of early life stages (Amin et al. 2016).

Histopathological studies are intensively being used as an important indicator for monitoring aquatic ecosystems since they provide a definite biological end-point in examining stressors exposed to specific target organs (Raibeemol and Chitra 2015). These techniques are rapid, sensitive, reliable, and comparatively inexpensive for studying the stress response of chemical and environmental stressors and are useful to assess the histopathological changes in tissues or organs occurred due to such stresses (Raibeemol and Chitra 2015). Therefore, histopathological changes observed in internal organs (e.g. kidney, liver, ovary) of fish are acknowledged as a fast and valid method to determine the damages caused by exposure to different stressors (Arellano et al. 2001).

Trichogaster fasciata, the banded gourami, locally called kholisa, has been used as a fish model for exposure studies. It is benthopelagic and prefers weedy environments such as estuaries, ponds, large rivers, ditches, lakes of Bangladesh, India, Myanmar, Nepal and Pakistan (Mitra et al. 2007). Due to short generation time, captive breeding (in the laboratory), easy acclimatization in aquarium and other laboratory conditions, this fish has become a popular model for aquatic stress studies in fish (Sumon et al. 2017). The objectives of the present research work were to determine the effects of salinity intrusion on important internal organs like liver, kidney and ovary tissues of a freshwater fish striped gourami ( $T$. fasciata) and to observe the abnormalities and deformities in these organs exposed to different sub-lethal concentrations of salinity.

\section{Materials and Methods}

Preparation of salt water and collection of experimental fish: Crude seawater salt was collected from the coastal district of Cox Bazar, Bangladesh. The crude salt was then mixed with freshwater in various concentrations in laboratory condition. Striped gourami ( $T$. fasciata) was used for the experiment as a test animal. Mature female of $T$. fasciata were collected from natural waters of Mymensingh . Live $T$. fasciata were then transported in well oxygenated 
polythene bags to the Wet Laboratory of the Faculty of Fisheries, Bangladesh Agricultural University and were kept in cement cistern with continuous water supply. They were reared under natural photoperiod and room temperature for conditioning. Fish were fed with commercial fish feed at the rate of $3 \%$ body weight and twice daily. Fishes were conditioned there for 21 days.

Experimental setup: After 21 days, the acclimatized fish were exposed to different concentrations of salt water for $96 \mathrm{hrs}$ to estimate the $\mathrm{LC}_{50}$ value. Probit Analysis of fish mortality records (24-, 48- and 96-h) helped determine $\mathrm{LC}_{50}$ value for $T$. fasciata against crude salt. Based on $\mathrm{LC}_{50}$, mature $T$. fasciata female were exposed to four sub-lethal concentrations of crude salt in water $(0,3,6$ and $9 \mathrm{ppt})$ in three replicates. Twelve $70 \mathrm{~L}$ plastic drums were used for fish-keeping, filled with chlorine-free groundwater, equipped with aerators, released with 10 fish per drum, feeding daily at 3\% of body weight and exposing for a period of 30 days. Unutilized feedstuffs and fecal wastes were cleaned everyday by siphoning. Water was exchanged on every 10th day and crude salt was added to maintain desired salinity of each treatment. Fishes were sampled on 30th day and fish kidney, liver and ovary were collected (and fixed in Bouin's fluid) for histopathological studies.

Histological procedures: The fixed kidney, liver and ovary tissues were dehydrated by passing through graded alcohol series and cleared by chloroform and embedded into paraffin. Embedded tissues were then sectioned at $5 \square \mathrm{m}$ thickness using a microtome. The sections, placed on slides like ribbons, were then stained with routine Haematoxylene-Eosin (H-E) protocols, followed by mounting with DPX and cover slip. Finally, the stained sections were observed under a microscope to detect the histopathological changes in kidney, liver and ovary tissues.

Statistical analysis: Values are expressed as means \pm standard deviation (SD). Data were analyzed by a one-way analysis of variance (ANOVA) followed by Tukey's post hoc test to assess statistically significant differences among different treatments. Statistical significance was set at $p<0.05$. Statistical analyses were performed using PASW Statistics 18.0 software (IBM SPSS Statistics, IBM, Chicago, USA).

\section{Results}

Effects of salt water on fish kidney: Kidney tissues collected from $T$. fasciata exposed to 0 ppt salinity did not show any histopathological alterations, associate with normal renal tubule (NRT) and Bowman's capsule (BC) (Fig. 1A). On the other hand, following abnormalities were observed in kidney tissues of $T$. fasciata exposed to salt water- vacuole (V) and cellular degeneration (CD) in 3 ppt (Fig. 1B), hemorrhage (H), disintegrated glomeruli (DG) and destructed renal tubule (DRT) in $6 \mathrm{ppt}$ (Fig. 1C) and CD, H and extensive vacuole (EV) in $9 \mathrm{ppt}$ (Fig. 1D).

Effects of salt water on fish liver: Liver tissues collected from $T$. fasciata exposed to $0 \mathrm{ppt}$ salinity did not show any histopathological alterations (Fig. 2A). On the other hand, following abnormalities were observed in liver tissues of $T$. fasciata exposed to salt water - hemorrhage $(\mathrm{H})$, vacuums $(\mathrm{V})$, degeneration of muscle (DM) and hepatic cell rapture (HCR) in 3 ppt (Fig. 
HISTOPATHOLOGICAL CHANGES IN STRIPED GOURAMI EXPOSED TO SALT WATER

2B), H, DM, and some melano macrophage cells (MMC) in 6 ppt (Fig. 2C) and V, DM, H and severe necrosis in 9 ppt (Fig. 2D).
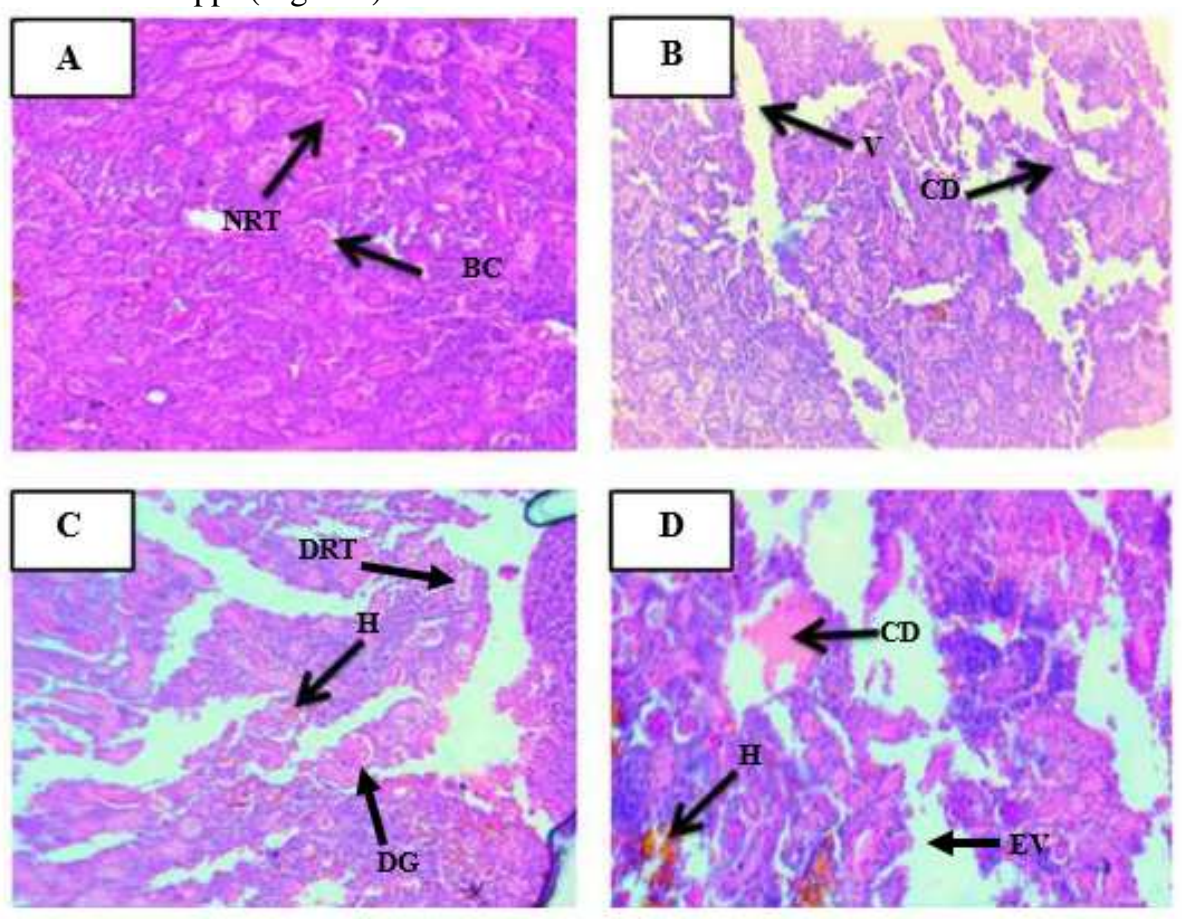

Fig. 1. Histopathological changes in $T$. fasciata kidney tissues exposed to sub-lethal concentrations of crude salt for 30 days. A, B, C and D correspond to $0,3,6$ and 9 ppt salinity, respectively.

Effects of salt water on fish ovary: Ovarian tissues collected from $T$. fasciata exposed to $0 \mathrm{ppt}$ salinity did not show any histopathological alterations (Fig. 3A). On the other hand, following abnormalities were observed in ovarian tissues of $T$. fasciata exposed to salt water - degenerated granulose layer (DGL), degenerated oocyte wall (DOW) and inter follicular space (IFS) in 3ppt (Fig. 3B), DGL and disrupted oocyte (DO) in 6ppt (Fig. 3C) and adhesion (AD), atretic follicle (AF) and DGL in 9 ppt (Fig. 3D).

\section{Discussion}

Effects of salt water on fish kidney: After 30 days exposure to salt water, histopathological changes in the kidney tissues of striped gourami were observed to be cellular degeneration, hemorrhage, destructed renal tubule, extensive vacuole and destructed glomeruli. Jashim (2013) reported that structural changes in the kidney of Barbus sharpeyi young were associated with adaptation at brackish water, which is similar to our findings. Apart from salinity, chemical stressors like pesticides are also potential aquatic environmental stressors that were found to alter histo-architectures of 
kidney and other internal organs in many fish species. Gambusia affinis exposed to chlorpyrifos was found to cause pathology in kidney tissues (Sabiha and Neelam 2013).
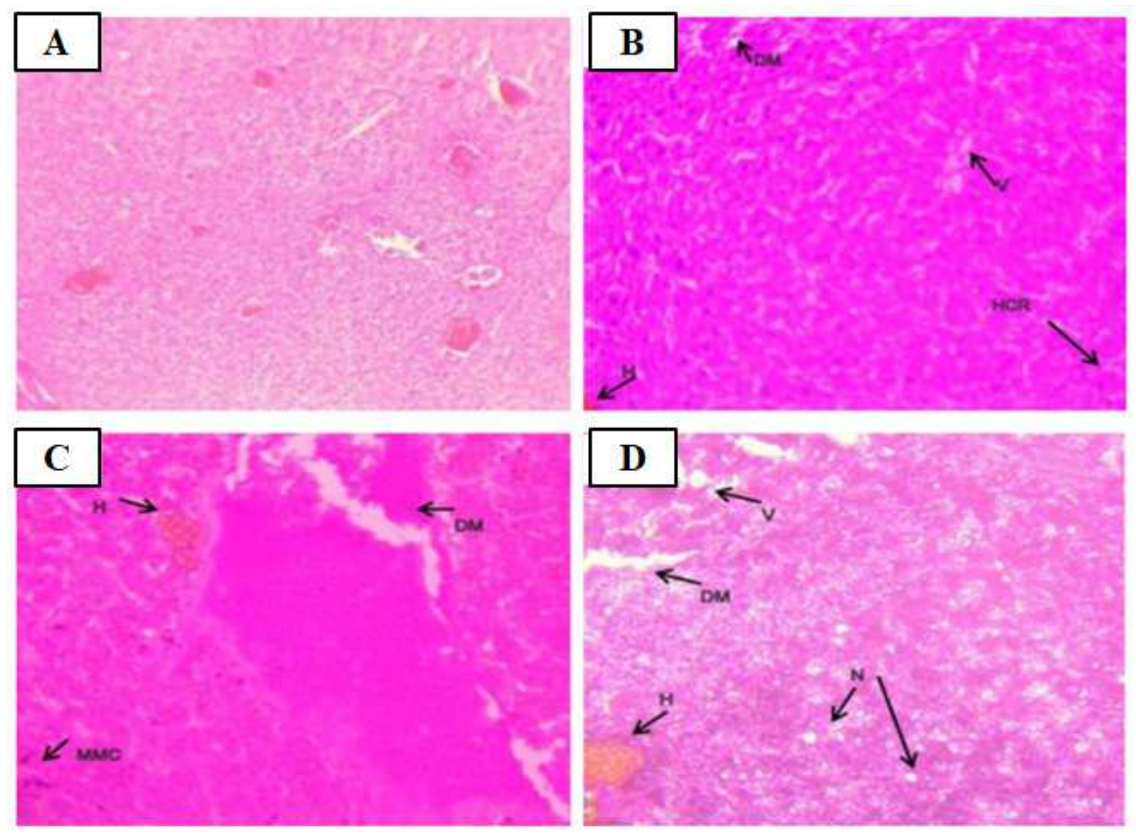

Fig. 2. Histopathological changes in $T$. fasciata liver tissues exposed to sub-lethal concentrations of crude salt for 30 days. A, B, C and D correspond to 0, 3, 6 and 9 ppt salinity, respectively.

In a study where rainbow trout was exposed to linuron herbicide, small cytoplasmic vacuoles and nuclear deformation in the epithelium of the proximal tubule of kidney were observed (Oulmi et al. 1995). Renal corpuscles, the blood-filtering component of the nephron of the kidney, were scattered. This might result in disorganization of renal corpuscles and resultant obstructions to physiological functions (Olufayo 2009). Sharmin et al. (2015) reported necrosis, disintegrated renal tubule, vacuole and shrunk glomerulus in common carp kidney tissues due to sub-lethal exposure to malathion. Hadi and Alwan (2012) reported deterioration of glomerulus, dilation of Bowman's space, cellular degeneration, hemorrhage, edematous fluid and shrinkage of renal corpuscle of Tilapia zillii kidney due to aluminum toxicity. Abnormalities in gill, liver, kidney and spleen of channel catfish were evident after an exposure of 72-h to $1.5 \mathrm{ppm}$ oxygen (Scott and Rogers 1980). These findings are more or less similar to the present findings where salinity was studied as an environmental stressor. 

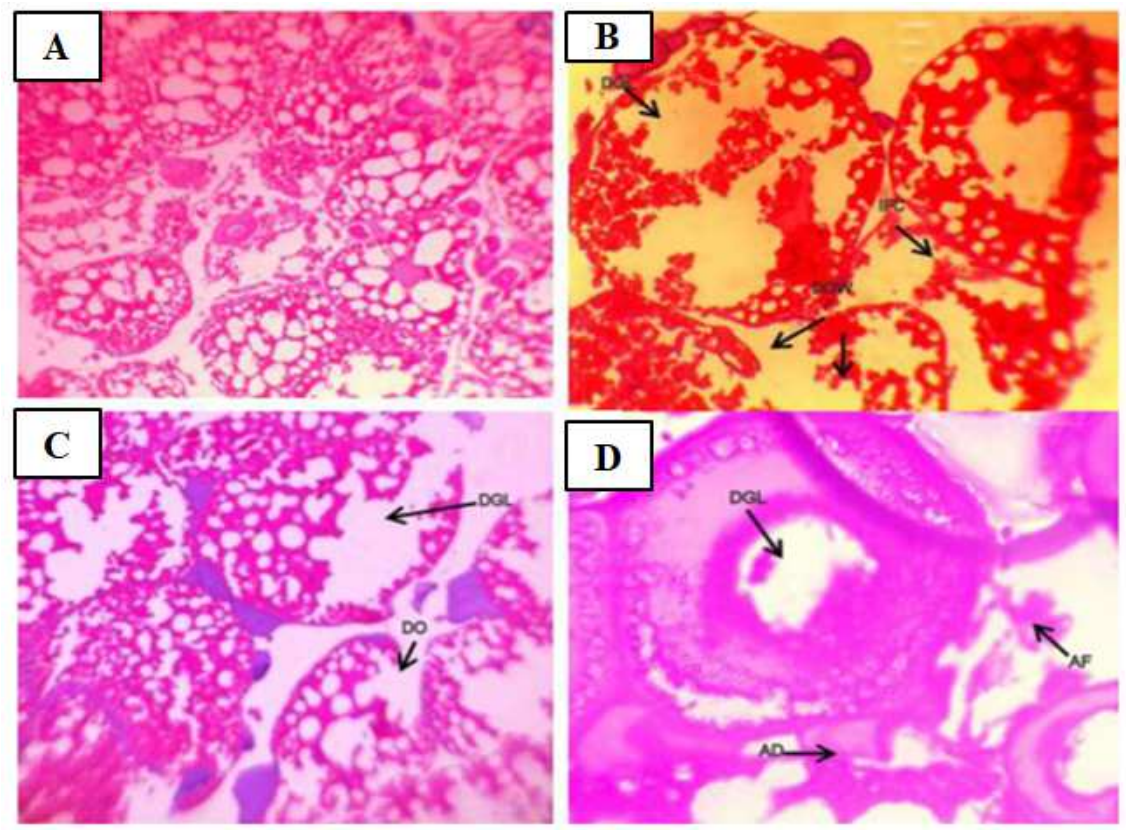

Fig. 3. Histopathological changes in $T$. fasciata ovarian tissues exposed to sub-lethal concentrations of crude salt for 30 days. A, B, C and D correspond to $0,3,6$ and 9 ppt salinity, respectively.

Effects of salt water on fish liver: At the end of the experiment, histo-architecture of $T$. fasciata liver tissues from $0 \mathrm{ppt}$ salinity exposure were found normal without any sign of necrosis; hepatocytes and other cells too, were found normal and systematically arranged. Tissue sample from fishes treated with salt waters showed mild vacuums, degeneration of muscle and rapture of hepatic cells causing hemorrhage which was similarly reported by Hossain et al. (2002). However, in T. fasciata exposed to higher salinities, there were marked degenerations of muscle, necrosis, severe melanomaccite cell, hemorrhage and vacuolation observed which agreed with the finding of Rahman et al. (2002) and Omitoyin et al. (1999). Kabir and Begum (1978) reported degenerations of muscles, necrosis of liver tissues, vacuolation in hepatic cells, rupture of blood vessels and degenerative hepatic cells of Heteropneustes fossilis exposed to 5, 10, and $20 \mathrm{ppm}$ diazinon for 25 days. Sharma (1979) reported that Channa punctatus exposed to a sub-lethal concentration $(0.01 \mathrm{ppm})$ of endrin resulted hypertrophy of hepatic cells and liver cord disarray, vacuolation of cytoplasm and necrosis, rupture of hepatic cell membrane and centrolobular necrosis. These findings are almost similar to the results of the present experiment.

Effects of salt water on fish ovary: After 30 day of exposure to three different salt water concentrations, the histo-architecture of ovary tissues showed degenerated oocyte wall, inter follicular space, degenerated granulose layer and adhesion. Similar findings were reported by Hossain et al. (2002) in the ovaries of Anabas testudineus and $C$. 
punctatus after exposure of 0.5 and $5.0 \mathrm{ppm}$ pesticide concentration of dimecron 100SCW. Histological observations of ovarian tissues of carp species Chalcalbur nustarichi, after 30 day exposure to $17 \beta$-estradiol and acetyl-cholinesterase ,revealed that the oocytes were degenerated in the perinucleolus and early cortical alveolus stages and the ovaries were full of somatic stromal tissues (Unal et al. 2007). Barua and Das (2002) reported that nucleus and cytoplasm organization changed due to exposure of $H$. fossilis to paper mill effluent for 20 days. C. punctatus exposed to $0.033 \mathrm{ppm}$ concentration of a synthetic pyrethroidcypermethrin showed that gross histo-anatomy of ovarian tissue reveals epithelial lesions, inflammatory responses, stoma hemorrhage, increased interstitium and shrinkage of yolk vesicles towards periphery. These findings suggest of delayed gonadal maturity due to reproductive impairments. As a result, ovulation process will be impaired and fish production will be affected (Srivastava et al. 2008).

\section{Literature Cited}

Amin, F.B., T. Farhana, G. M. Mostakim, M. M. Zahangir, M.M. Mishu, and M. S. Islam, 2016. Behavioral and physiological stress responses of Java barb (Barbonymus gonionotus) to environmental salinity challenge. J. Aquac. Eng. Fish. Res., 2(4): 176-184.

Arellano, J.M., J.B.Ortiz, M.L.G.Canales, C. Sarasquete, 2001. Histopathological alterations and induction of cytochrome P-450 1A in the liver and gills of the gilt head seabream (Sparus aurata) exposed to 2, 3, 7, 8-tetrachloro dibenzo-pdioxin. Histochem. J. 33:663674.

Baruah, B.K. and M. Das, 2002. Histopathological changes in ovary of fish Heteropneustes fossilis exposed to paper mill effluent. Int. J. Environ. Sci. Technol., 3: 29-32

Bhuiyan, M.J.A.N. and D. Dutta, 2012. Assessing impacts of sea level rise on river salinity in the Gorai river network, Bangladesh. Estuar. Coast. Shelf Sci., 96:219-227.

Cengiz, E. I., 2006. Gill and kidney histopathology in the freshwater fish Cyprinus carpio after acute exposure to deltamethrin. Environ. Toxicol. Pharmacol.,22: 200-204.

Hadi, A.A. and S.F.Alwan, 2012. Histopathological changes in gills, liver and kidney of fresh water fish, Tilapia zillii, exposed to aluminum. Int. J. Ppharm. Life Sci., 3(11): 2071-2081.

Hossain, Z., M.Z.Rahman, M.F.A.Mollah, 2002. Effect of Dimecron-100 SCW on Anabas testudineus, Channa punctatus and Barbodes gonionotus. Indian J. Fish., 49: 405-417.

Jahan, A., T.T.Nipa, S.M.M.Islam, M.H.Uddin, M.S.Islam, and M. Shahjahan, 2019. Striped catfish (Pangasianodon hypophthalmus) could be suitable for coastal aquaculture. J. Appl. Ichthyol., 35: 994-1003.

Jasim, B.M., 2013. Structural changes in the kidney of Barbus sharpeyi (Cyprinidae) youngs adapted to brackish water. ARPN J. Agric. Biol. Sci., 8(4): 357-363.

Kabir, S.M.H. and R. Begum, 1978. Toxicity of three organophosphorus insecticides to Singh fish Heteropneustes fossilis (Bloch). Dhaka Univ. Stud., 26: 115-122.

Larsen, P.F., E.E.Nielsen, K. Meier, P.A.Olsvik, M.M.Hansen, and V. Loeschcke, 2012. Differences in salinity tolerance and gene expression between two populations of Atlantic cod (Gadus morhua) in response to salinity stress. Biochem. Genet.,50:454 -466. 
HISTOPATHOLOGICAL CHANGES IN STRIPED GOURAMI EXPOSED TO SALT WATER

Mitra, K., V.R.Suresh, G.K.Vinci, N.N.Mazumdar, and D.K.Biswas, 2007. Biology and fishery of banded gourami, Colisa fasciata (Bloch and Schneider, 1801) in a floodplain wetland of Ganga river basin. Asian Fish. Sci., 20: 409-423.

Olufayo, M. O., 2009. Haematological characteristics of $C$. gariepinus juveniles exposed to derris root powder. African J. Food, Agric. Nutri. Dev., 9(3): 921-933.

Omitoyin, O.B., A. O. Ogunsanmi, and B. T. Adeina, 1999. Studies on actuate toxicity of Piscicidal plant extracts (Tetrapleura tetraptera) on tilapia (Sarotherrodon galilaeus) fingerlings. J. Anim. Sci., 2: 91-97.

Oruce, E.O. and D. Usta, 2007. Evaluation of oxidative stress responses and neurotoxicity potential of diazinon in different tissues of Cyprinuscarpio. Environ. Toxicol. Pharmacol.,23: 48-55.

Oulmi, Y., R.D.Negele, and T. Braunbeck, 1995. Cytopathology of liver and kidney in rainbow trout (Oncorhynchus mykiss) after long-term exposure to sub lethal concentrations of linuron. Dis. Aquat. Org., 21:35-52.

Overton, J. L., M. Bayley, H. Paulsen, and T. Wang, 2008. Salinity toler $\square$ ance of cultured Eurasian perch, Perca fluviatilis L.: Effects on growth and survival as a function of temperature. Aquaculture, 277: 282-286.

Rahman, M.Z., Z. Hossain, M.F.A.Mollah, and G.U. Ahmed, 2002. Effect of Diazinon 60EC on Anabas testudineus, Channa punctatus and Barbodesgonionotus. Naga: 25: 8-12.

Raibeemol, C., 2015. A study on median lethal concentration and behavioral responses of cichlid fish, Etroplus maculatus (Bloch, 1795) exposed to organophosphorus insecticide, chlorpyrifos. Global J. Res. Anal., 4(11): 15-17.

Sabiha, K. and S. Neelam, 2013. Histopathological alterations in the kidney of Gambusiaaffinisafter exposure to chlorpyrifos. Int. J. Chem. Pharmceut. Sci., 1: 122-127.

Scott, A.L. and W.A.Rogers, 1980. Histopathological effects of prolonged sub-lethal hypoxia of channel catfish, Ictalurus punctuates. J. Fish Dis., 3(4): 305-316.

Sharma, K. 1979.Endrin induced hepatic injury in Channa punctatus. Indian J. Fish., 26: 250253.

Sharmin, S., M.Shahjahan, M.A.Hossain, M.A.Haque, and H. Rashid, 2015. Histopathological changes in liver and kidney of common carp exposed to sub-lethal doses of malathion. Pakistan J. Zool., 47(5): 1495-1498.

Srivastava, R.K., K.K.Yadav, and S. P. Trivedi, 2008. Devicyprin induced gonadal impairment in a freshwater food fish, Channa punctatus (Bloch). J. Environ. Biol., 29: 187-191.

Sumon, K.A., S.Saha, P. Van den Brink, E.T.H.M.Peeters,R.H.Bosma, and H. Rashid, 2017. Acute toxicity of chlorpyrifos to embryo and larvae of banded gourami Trichogaster fasciata. J. Environ. Sci. Health, Part B, 52(2): 92-98.

Unal, G., V. Turkoglu, A.R.Oguz, and B. Kaptaner, 2007. Gonadal histology and some biochemical characteristics of Chalcalbur nustarichi (Palls, 1811) having abnormal gonads. Fish Physiol. Biochem., 331: 53-165.

Velmurugan B., M. Selvanayagama, E.I. Cengiz, and E. Unlu, 2007. Histopathology of lambda-cyhalothrin on tissues (gill, kidney, liver and intestine) of Cirrhinus mrigala. Environ. Toxicol. Pharmacol., 24: 286-291.

Zhang, E., H.H.G. Savenije, H. Wu, Y. Kong, and J. Zhu, 2011. Analytical solution for salt intrusion in the Yangtze estuary, China. Estuar. Coast. Shelf Sci., 91: 492-501. 